\title{
Parents' preferences for the organization of long-term follow-up of childhood cancer survivors
}

Vetsch Janine ${ }^{1,2,3}$, Rueegg Corina $\mathrm{S}^{.1,4}$, Mader Luzius ${ }^{1}$, Bergstraesser Eva ${ }^{5}$, Diezi Manuel ${ }^{6}$, Kuehni Claudia E. , Michel Gisela ${ }^{1,7}$ For the Swiss Paediatric Oncology Group*

${ }^{1}$ Department of Health Sciences \& Health Policy, University of Lucerne, Frohburgstrasse 3, 6002 Lucerne, Switzerland

${ }^{2}$ Discipline of Paediatrics, School of Women's and Children's Health, UNSW Medicine, University of New South Wales, Kensington, NSW, Australia, 2031.

${ }^{3}$ Kids Cancer Centre, Sydney Children's Hospital, Randwick, NSW, Australia, 2031.

${ }^{4}$ Oslo Centre for Biostatistics and Epidemiology, Department of Biostatistics, Institute of Basic Medical Sciences, University of Oslo, P.O. Box 1122 Blindern, 0317 Oslo, Norway

${ }^{5}$ Department of Oncology/Hematology, University Children's Hospital Zurich, Steinwiesstrasse 75, 8032 Zurich, Switzerland

${ }^{6}$ Paediatric Hemato-Oncology Unit and Division of Clinical Pharmacology, rue du Bugnon 46, 1011 Lausanne CHUV, Switzerland

${ }^{7}$ Institute of Social and Preventive Medicine, University of Bern, Finkenhubelweg 11, 3012 Bern, Switzerland

*Swiss Paediatric Oncology Group (SPOG) Scientific Committee: Prof. R. Ammann MD, Bern; R. Angst MD, Aarau; PD M. Ansari MD, Geneva; PD M. Beck-Popovic MD, Lausanne; P. Brazzola MD, Bellinzona; J. Greiner MD, St. Gallen; Prof. M. Grotzer MD, Zurich; H. Hengartner MD, St. Gallen; Prof. T. Kuehne MD, Basel; Prof. K. Leibundgut MD, Bern; Prof. F. Niggli MD, Zürich; PD J. Rischewski MD, Lucerne; Prof. N. von der Weid MD, Basel.

\section{Corresponding author:}

Gisela Michel, Department of Health Sciences and Health Policy, University of Lucerne

Frohburgstrasse 3, 6002 Luzern, Switzerland

Ph:+41 41 2295955, Fax: +41 41 2295635, E-mail: gisela.michel@unilu.ch

\section{Financial support:}

This work was supported by the Swiss National Science Foundation (100019 153268/1; Ambizione grant PZ00P3_121682/1 and PZ00P3-141722 to GM). JV is supported by the Swiss National Science Foundation (Doc.Mobility grant P1LUP3_162120). CSR has received funding from the European Union Seventh Framework Programme (FP7-PEOPLE-2013-COFUND) under grant agreement $n^{\circ} 609020$ - Scientia Fellows. The Swiss Childhood Cancer Survivor Study was funded by the Swiss Cancer League (KLS-2215-02-2008, KFS-02631-082010, KLS-02783-02-2011). The work of the Swiss Childhood Cancer Registry is supported by the Swiss Pediatric Oncology Group (www.spog.ch), Schweizerische Konferenz der kantonalen Gesundheitsdirektorinnen und direktoren (www.gdk-cds.ch), Swiss Cancer Research (www.krebsforschung.ch), Kinderkrebshilfe Schweiz (www.kinderkrebshilfe.ch), Ernst-Göhner Stiftung, Stiftung Domarena and National Institute of Cancer Epidemiology and Registration (www.nicer.ch). 


\begin{abstract}
Parents take an important role in follow-up of young cancer survivors. We aimed to investigate 1) parents' preferences for organization of follow-up (including content, specialists involved and models of care), and 2) parents' and children's characteristics predicting preference for generalist versus specialist-led followup. We sent a questionnaire to parents of childhood cancer survivors aged 11-17years. We assessed on a four-point Likert scale (1-4), parents' preferences for organization of long-term follow-up. Proposed models were: telephone/questionnaire, general practitioner (GP) (both categorized as generalist for regression analysis); and pediatric oncologist, medical oncologist or multidisciplinary team (MDT) (categorized as specialists). Of 284 contacted parents 189 responded (67\%). Parents welcomed if visits included checking for cancer recurrence (mean=3.89), late effects screening (mean=3.79), taking patients seriously (mean $=3.86, \mathrm{SD}=0.35)$ and competent staff $(\mathrm{mean}=3.85)$. The preferred specialists were pediatric oncologists (mean=3.73). Parents valued the pediatric oncologist model of care (mean=3.49) and the MDT model (mean=3.14) highest. Parents of children not attending clinic-based follow-up $(\mathrm{OR}=2.97, \mathrm{p}=0.009)$ and those visiting a generalist $(\mathrm{OR}=4.23, \mathrm{p}=0.007)$ favored the generalist-led model. Many parents preferred a clinic-based model of follow-up by pediatric oncologists or a multidisciplinary team. However, parents also valued the follow-up care model according to which their child is followed up.
\end{abstract}

Key words: parents of childhood cancer survivors; pediatric oncology; follow-up care; models of care; cancer registry, Europe

\section{INTRODUCTION}

Lifelong follow-up care is recommended for most childhood cancer survivors. The goal of follow-up is to identify and treat relapse and late effects early, and provide age-adapted information about cancer, treatment, potential late effects and health behavior. (Bhatia \& Meadows, 2006; Hudson , et al., 2013; Oeffinger , et al., 2006; Taylor, Absolom, Snowden, Eiser, \& Late Effects Group, 2012). Guidelines have been developed to provide recommendations for risk-stratified long-term follow-up care (Children's Oncology Group, 2008; Scottish Intercollegiate Guidelines Network (SIGN), 2004; Wallace, Thompson, Anderson, \& Guideline Development, 2013). Various models of care have been described and compared (Heirs , et al., 2013) such as follow-up by telephone (James, Guerrero, \& Brada, 1994), multidisciplinary team (MDT) (Carlson, Hobbie, Brogna, \& Ginsberg, 2008; Edgar \& Wallace, 2008), pediatric oncologist (Haddy \& Haddy, 2010), general practitioners (GP) (Schmidt, et al., 2010) or shared-care models (Blaauwbroek, Tuinier, Meyboom-de Jong, Kamps, \& Postma, 2008). In many countries, none of the models have been implemented and long-term follow-up is not standardized.

In Switzerland, childhood cancers survivors are regularly followed-up by their pediatric oncologist into their early twenties, and are then usually discharged to a GP or medical oncologist. Others may continue follow-up with their pediatric oncologist longer into adulthood.
Prior to setting up a specific model of follow-up care survivors' and their parents' opinions and preferences for the organization of care should be assessed (Aslett, Levitt, Richardson, \& Gibson, 2007; Earle, Davies, Greenfield, Ross, \& Eiser, 2005). Survivors' opinions and preferences have previously been studied (Michel, et al., 2016; Michel, et al., 2009). Parents' expectations of follow-up care have only been addressed in a small focus group study in the UK (Earle, et al., 2005): parents desired medical facts and written test results for reassurance, information on psychosocial consequences, and wanted to have the possibility to meet other families with a child survivor. Parents did not value the GP model since they perceived that specialist knowledge was not available.

Parents take an important role in follow-up care for many reasons: they are most aware about the child's medical history but also provide things such as transportation or reminding about doctor's appointment. We thus aimed to investigate 1) parents' preferences for the organization of follow-up care (including content, specialists involved and different models of care). These outcomes were assessed for both children attending and not attending clinic-based follow-up. 2) We investigated associations of socio-demographic characteristics of parents and children's clinical factors with preferences for generalist versus specialist-led follow-up. 


\section{METHODS}

\section{Sample and procedure}

The Swiss Childhood Cancer Registry (SCCR) is a national population-based cancer registry including all cancer patients, diagnosed with leukemia, lymphoma, central nervous system (CNS) tumor, malignant solid tumor or Langerhans cell histiocytosis at age $<21$ years in Switzerland since 1976 (Michel, et al., 2007; Michel, et al., 2008). The Swiss Childhood Cancer Survivor Study (SCCSS) is a nationwide, long-term follow-up survey of the SCCR including a baseline (2007-2011) and a follow-up questionnaire (2010-2012).

The baseline questionnaire included all patients registered in the SCCR who were diagnosed between 1976-2005, aged $<21$ years and survived for $\geq 5$ years (Kuehni, et al., 2012a). Parents of survivors aged $\leq 15$ years completed the questionnaire for their children, whereas survivors $16+$ years completed their own questionnaire.

The follow-up questionnaire was sent approximately 2 years later. Parents who filled in the baseline questionnaire were contacted again if their child who had cancer was aged $11-17$ years at time of follow-up study (eligible $\mathrm{N}=306$; Supplemental Figure 1). They received the questionnaire with a prepaid return envelope, and if they did not reply within two months, a reminder letter with another questionnaire. Questionnaires were available in German and French and focused on topics related to follow-up care.

Ethics approval was provided through the general cancer registry permission of the SCCR (The Swiss Federal Commission of Experts for Professional Secrecy in Medical Research) and a non-obstat statement from the ethics committee of the canton of Bern declaring that the ethics committee did not object the conduct of the study.

\section{Measurements}

The follow-up survey of the SCCSS focused on follow-up care and psychological outcomes. Follow-up care after childhood cancer was introduced on the front page of the questionnaire as follow-up appointments of their child due to the previous severe disease.

\section{Outcome}

Items were purpose designed and based on a previous study in the UK (Michel, et al., 2009). What are the reasons for follow-up: Parents rated the importance (1="not at all important" to 4="very important"; this scale was used in all questions where parents had to rate importance) of different reasons for attending follow-up (nine items).

What should be included in follow-up: We asked parents about the perceived importance of four medical aspects and eight general aspects of follow-up (Figure 1A).

What is important during appointments: Parents rated the importance of 10 organizational aspects (Figure 1A).

Who should be involved in follow-up: Parents rated the importance of different medical and other specialists involved in follow-up (Figure 1B).

Models of care: We provided a short description of five different models of follow-up care by: a) telephone/questionnaire, (led by a nurse referring patients to specialist care if needed), b) GP-led and referring patients to a specialist if needed, c) pediatric oncologist who originally treated the survivor, d) medical oncologist, e) multidisciplinary team (MDT) in a hospital (defined as including several specialists such as oncologists, endocrinologists, psychologists, social workers and nurses, all of whom are accessible during one appointment). For each model we asked parents' agreement to four items (1="don't agree at all" to 4="completely agree"): 'it would suit my child', 'I am afraid that health problems are not detected', 'I am not satisfied with this kind of follow-up', this model of follow-up is appropriate for the needs of their child.

Explanatory variables assessed by questionnaire We assessed parents' sex, age at study, migration background (migration if they were not Swiss citizens since birth or not born in Switzerland), language region (German vs. French), parents' employment status (employed vs. not employed), and education (three categories: primary (compulsory schooling including vocational training/apprenticeship); secondary (teachers/technical and commercial schools etc.); tertiary (university and university of applied sciences; Table 1) (Kuehni, et al., 2012b).

Additionally, we asked parents if their child still attended follow-up: 1) 'yes, my child still attends regular follow-up appointments'; 2) 'yes, my child still has irregular follow-up appointments'; 3) 'no, regular follow-up is completed, but my child goes to the doctor for any cancer-associated complications'; 4) 'no, regular follow-up is completed and my child has not seen the doctor 
for a while'. A binary variable was created: attenders (responses 1 or 2) and non-attenders (responses 3 or 4). Parents indicated on a list which doctors were involved in current care. This was coded as "specialist care" if parents listed at least one specialist and "generalist" if only a GP was indicated. Parents were asked whether they are currently involved in follow-up care (parental involvement=yes/no) (Vetsch, et al., 2016). Concerns of parents about consequences of their child's illness were assessed by the question "How concerned are you about consequences of your child's illness?" (adapted from the Brief Illness Perception Questionnaire (IPQ) using a 0to-10 response scale) (Broadbent, Petrie, Main, \& Weinman, 2006). The response was divided in three categories (no: $0-2$, medium: $3-6$, and high concerns: 7-10).

From the baseline questionnaire of the SCCSS we extracted information about parent-reported late effects of the survivor (yes/no) (Kuehni, et al., 2012a).

\section{Clinical variables of the child extracted from the SCCR}

We extracted medical information on cancer diagnosis and treatment of the child from the SCCR. Cancer diagnosis was classified according to the International Classification of Childhood Cancer (third edition) (Steliarova-Foucher, Stiller, Lacour, \& Kaatsch, 2005). For the analyses we recoded diagnosis into six major groups: leukemia, lymphoma, CNS tumors, neuroblastoma, bone tumor/soft tissue sarcoma (STS) and other tumors. Treatment was coded as: surgery only, chemotherapy (without radiotherapy \pm surgery), radiotherapy ( \pm surgery and/or chemotherapy) and stem cell transplantation (SCT; may have had surgery and/or chemotherapy and/or radiotherapy). The type of treating hospital was divided into university and regional hospital. Age at diagnosis was divided into three categories: 0-1 year, 2-4 years, $\geq 5$ years. We have chosen these categories because they might influence risk for late effects and preferences for follow-up care. Age at study was divided into three categories: $<14$ years, 1415 years, $>15$ years. Time since diagnosis was divided into three categories 5-9 years, 10-14 years and 15-17 years. Relapse was coded yes/no.

\section{Analyses}

Analyses were performed using Stata 13.1 (StataCorp, College Station, TX).

We used descriptive statistics to compare participants and non-participants of the study. For aim 1 we calculated means of the responses for each item. Paired t-tests were used to compare the means of clinical and supportive reasons. Hotelling t-test was used for the comparison of more than two means. Principal component analysis was used to test individual item loading onto different factors. The preference-score for each model of care was calculated as the overall mean of the four items assessed for each model. Two items had to be reverse coded such that higher scores indicated higher agreement (1-4). For each parent we determined the model with the highest preference-score. We then calculated the proportion of parents indicating each respective model as their preferred one (Figure 2) and stratified it by the model their child is currently attending (Figure 3 ). Parents could have more than one model reaching the highest preference-score.

To analyze difference in preferences between attenders and non-attenders we used t-test and chi $^{2}$-test. Bonferroni correction was used to correct for multiple testing.

For aim 2 we determined the model with the highest mean for each parent and created a binary variable indicating if GP or telephone/questionnaire follow-up (generalist follow-up=1) or any other follow-up model was rated highest (pediatric, medical oncologist, MDT: specialist follow-up=0, Table 2). Telephone/questionnaire and GP led model were grouped into generalist model because survivors would first contact a health care provider not necessarily specialized in pediatric oncology and only be referred to a specialist if needed. We used univariable logistic regression to investigate associations of parents' and their child's characteristics with the preferences for generalist versus specialist follow-up.

\section{RESULTS}

Of 306 eligible parents, we traced and contacted 284 (Supplemental Figure 2). Of those contacted, $189(67 \%)$ responded. The mean age of parents was 46.1 years $(\mathrm{SD}=4.8$, range 33.559.5 years), mean age of the child at study was 14.8 years $(\mathrm{SD}=1.8$, range $10.7-18.0$ years $)$, mean age at diagnosis was 3.4 years (SD 2.5 range 0 9.2 years) and the mean time since diagnosis 11.3 years (SD 2.5, range 6.8-17.2 years; Table 1). Most children were diagnosed with leukemia $(39.2 \%)$ followed by CNS tumors (18.0\%). Participating and non-participating parents were similar in socio-demographic and clinical characteristics (Table 1). 
1) Parents' preferences for organization of follow-up care

What are the reasons for follow-up: Factor analysis revealed two scales: supportive care (get reassurance about health, talk to staff who understand my child has been through, get advice about how to stay healthy, receive psychological support, get advice about everyday things) and clinical care (get information about late effects, check the cancer has not come back, help clinic staff learn more about late effects, get the best medical care). Cronbach's alpha, a measure for internal consistency, was good for supportive care: $\alpha=0.73$; but low for clinical care $\alpha=0.58$. Parents valued clinical reasons (mean $=3.75$, $\mathrm{SD}=0.33$ ) higher than supportive reasons (mean=3.11, $\mathrm{SD}=0.58 ; \mathrm{p}<0.001$ ).

What should be included in follow-up: Among clinical aspects, parents rated check for cancer recurrence as most important (mean $=3.91$, $\mathrm{SD}=0.36$; Figure 1A), before screen for late effects (mean $=3.79, \quad \mathrm{SD}=0.45 ; \quad \mathrm{p}<0.001)$ and information on potential late effects (mean $=3.65$, $\mathrm{SD}=0.57 ; \mathrm{p}<0.001)$. Regarding general aspects, knowing about risks for their child's offspring was rated as most important (mean=3.12, $\mathrm{SD}=0.82$ ) whereas exchange with other former patients $\quad($ mean $=2.29, \quad \mathrm{SD}=0.91) \quad$ and religion/spirituality were rated least important (mean=1.68, $\mathrm{SD}=0.79$ ).

What is important during appointments: Parents rated patient is taken seriously (mean $=3.86$, $\mathrm{SD}=0.35$; Figure 1A) and competent staff (mean=3.85, $\mathrm{SD}=0.37$ ) as most important aspects, and significantly more important than the quality of relationship to medical staff (mean $=3.75, \mathrm{SD}=0.52 ; \mathrm{p}=0.002$ ). Least important were short consultation (mean $=2.55, \mathrm{SD}=0.81$ ) and meet former patients (mean $=2.16, \mathrm{SD}=0.82$ ).

Who should be involved in follow-up: When we asked about staff who should be involved in follow-up care parents rated the pediatric oncologist as most important (mean=3.73, $\mathrm{SD}=0.68$ ) and significantly more important than general practitioners (mean $=3.28, \quad \mathrm{SD}=0.89$; $\mathrm{p}<0.001 ; \quad$ Figure 1B). Radiotherapist (mean $=2.02, \quad \mathrm{SD}=0.95$ ) and social workers (mean $=1.95, \mathrm{SD}=0.90$ ) were least important.

Models of follow-up care: For each model, we calculated the overall mean score among all parents. Additionally, we calculated the number of parents who had the highest preference-score for the respective model compared to all other models (Figure 2). Most parents preferred follow-up by a pediatric oncologist $(\mathrm{N}=117$, $61.9 \%$, mean $=3.49, \mathrm{SD}=0.65$ ), followed by MDT
$(\mathrm{N}=72,38.1 \%$, mean $=3.16, \mathrm{SD}=0.74 ; \mathrm{p}<0.001)$, GP $(\mathrm{N}=55,29.1 \%$, mean $=2.71, \mathrm{SD}=0.97)$ and medical oncologist $(\mathrm{N}=54 ; 28.6 \%$, mean $=2.84$, $\mathrm{SD}=0.86$ ). Only few parents preferred the telephone/questionnaire model $(\mathrm{N}=9,4.8 \%$, mean $=1.81, \mathrm{SD}=0.79$ ). The pediatric oncologist and MDT model were rated significantly higher than the other three models (all $p<0.001$ ). When stratified for the model their child is currently attending, parents whose child attended specialist follow-up preferred the pediatric oncologist model (44.6\%) followed by MDT (21.6\%). Parents whose child saw a generalist preferred the GP model (29.1\%) but also had preferences for specialist-led follow-up care (Figure 3).

There was no difference in preferences for follow-up between parents of attenders and nonattenders after Bonferroni correction (Supplemental Table 1).

2) Associations with parents' preferences for generalist versus specialist-led follow-up:

We used logistic regression analyses to determine characteristics of parents and clinical characteristics of the child associated with preferences for generalists follow-up (GP and telephone/questionnaire) versus specialist followup (pediatric or medical oncologist, MDT; Table 2). Parents of children not attending follow-up care $(\mathrm{OR}=2.97$, CI $1.33-6.60, \mathrm{p}=0.009)$ or already visiting a generalist for follow-up $(\mathrm{OR}=4.23$, CI 1.84-9.71, $\mathrm{p}=0.007)$ rated the generalist model higher. A trend could be seen for lower preferences for generalist follow-up care for parents of children who had had a relapse $(\mathrm{OR}=0.23$, CI $0.03-1.78, \mathrm{p}=0.083)$ and who had been treated in a regional hospital $(\mathrm{OR}=0.31$, CI 0.07-1.39, $\mathrm{p}=0.080$ ).

\section{DISCUSSION}

We found that clinical reasons to attend followup were more important than supportive reasons to parents of childhood cancer survivors aged 1117 years. Medical aspects such as checking for cancer recurrence or screening for late effects were rated as most important. Parents wanted that their child is taken seriously and competent staff is available. Pediatric oncologists and GPs were rated as the preferred doctors. Parents' preferred model of care was pediatric oncologist-led follow-up or follow-up by a MDT. The generalist model was only favored by parents of children not attending follow-up care at a treating clinic or who already see a generalist. 
The importance of medical aspects during follow-up was already reported in previous studies (Christen , et al., 2016; Earle , et al., 2005; Eiser, Levitt, Leiper, Havermans, \& Donovan, 1996; Michel , et al., 2016; Michel , et al., 2009). We reported that screening for late effects and check for cancer recurrence was rated most important for parents which are in line with what survivors reported. Parents want to be reassured about the cancer and know that their child is in best current health. A focus group analysis of parents of survivors aged 13-25 years showed that it is important to learn about risks for future health but also about how to stay healthy (Earle, et al., 2005). This is in contrast to our results where the general aspects such as risk for offspring were rated less important. The survivors in our samples are young and future health might not be of biggest concern, however parents and survivors should be informed that many years after diagnosis the risk for cancer recurrence diminishes and follow-up care is of higher importance to screen for late effects and learn about healthy lifestyle (Reulen, et al.).

When we asked for the specialist which should be involved parents preferred the pediatric oncologist followed by the GP. This preference for the pediatric oncologist was in line with another Swiss study on childhood cancer survivors (Michel, et al., 2016). In contrast to our findings a previous focus group reported that follow-up at a GP was evaluated as not appropriate since the specialist knowledge was lacking, whereas clinics led by specialist nurses were perceived as more acceptable, in offering both specialist expertise and opportunities for appropriate feedback (Earle, et al., 2005). However, these survivors were still in clinicbased follow-up most likely by a pediatric oncologist and therefore possibly favoring this specialist. Even though second highest in our study, another study in the US on survivors showed that follow-up by primary care physicians was rated highest and the late effects specialist second highest only (Zebrack, et al., 2004). Concerning might be that other studies reported that generalists lack knowledge and information on potential late effects or comfort of care for childhood cancer survivors (Lawrence, McLoone, Wakefield, \& Cohn, 2016; Mertens, et al., 2004). Therefore, a close collaboration with specialist should be guaranteed and educational interventions for GPs if required organized. A Dutch study showed that GP are willing to follow-up childhood cancer survivors in a shared-care model, however they saw lack of information and communication as a barrier (Blaauwbroek, et al., 2007). Therefore written treatment summaries or a passport for care should be provided and help the GP guide through recommended screening and follow-up care processes (Horowitz, Fordis, Krause, McKellar, \& Poplack, 2009). Such a passport will be implemented across Switzerland within the next years.

We additionally showed that most parents preferred follow-up care by a pediatric oncologist or a MDT led model. The telephone/questionnaire led model was least preferred. This is in line with two other studies among survivors who reported the pediatric oncologist-led follow-up as most important and the telephone/questionnaire follow-up least important (Michel, et al., 2016; Michel , et al., 2009). However, in the UK they only included survivors who attended clinic-based follow-up which was most likely led by a pediatric oncologist. Also expert committees have often favored long-term follow-up care clinics led by a MDT because late effects might be diverse and complex (Wallace, et al., 2001). With the ever growing population of survivors, follow-up care by pediatric oncologists however will not be feasible and manageable in Switzerland and MDT models might be too cost intensive. Therefore, in Switzerland many survivors are transitioned to a GP. Our results also indicated that parents of Swiss survivors still seeing a pediatric oncologist favor the pediatric oncologist-led follow-up, and parents whose children see a GP favor the generalist model. These parents also know specialist care from the first 5-10 years follow-up by the pediatric oncologist. Our results thus suggest that a riskstratified approach where low-risk survivors are transferred to GP-led follow-up could meet parents' preferences. These findings are supported by another Swiss study where we showed that adolescent and young adult survivors preferred follow-up by medical oncologists, most of whom were treated by medical oncologists (Christen, et al., 2016). As shown in another study on adult survivors satisfaction with care did not depend on the clinic type but rather on shorter waiting time and possibilities to discuss health concerns (Absolom, et al., 2006). Parents and survivors preferences and satisfaction of care should be taken into account as it might ensure future attendance in follow-up. 
We found no other clinical or socio-demographic associations for preferences for generalist-led follow-up care. Neither diagnosis nor late effects were associated with different preferences for follow-up care. However, there was some indication for a generalist preference in parents of survivors who did not have a relapse and those treated at a university hospital. This might suggest that preferences do not reflect the risk for late effects.

Our results and previous findings suggest that survivors and parents might be happy and feel comfortable with the model of care their children are currently receiving. Preference of care might be related to the satisfaction of care even though not measured in our study. Parents' preferences of care should therefore be considered early on and, if possible, follow-up care should be framed taking their preferences into account. Being the primary caregiver of young survivors their preference and satisfaction of care might ensure later attendance at follow-up care. However, parents should also be given adequate assurance and support in taking the decision on the future health care provider. Alternative models and individual preferences of long-term follow-up should be discussed. Additionally, both health care providers and primary caregivers might profit from written treatment summaries and survivorship care plans and guarantee adequate follow-up. A risk-stratified approach, where survivors receive follow-up care depending on diagnosis, and treatment (indicating their risk for late effects) might be the most adequate approach (Eiser, et al., 2006). However, for Switzerland such an approach has so far not been implemented (Rebholz, et al., 2011).

A limitation of this study is self-selection: parents of specific groups such as parents with greater interest in follow-up care or with higher needs may have been more willing to complete the questionnaire, others have been excluded because they did not complete the baseline questionnaire. Additionally, we only contacted one parent, mostly mothers, and thus information on preferences of the other parent is lacking. Also, we did not contact the survivors themselves in these families, and thus the preference of care of survivors is lacking. Another limitation is that we cannot tell if this is what parents really prefer or what they have been told to do by the treating physician. Further, we were not able to stratify survivors according to their risk because detailed information on exact treatment was lacking. The small sample size resulted in reduced precision and large confidence intervals. Therefore, only limited stratification of results was possible. Other limitations are the low reliability of the scale "clinical reasons" and the self-reported late effects.

Despite the relatively small sample size, this is a study with a rather large sample of parents of childhood cancer survivors compared to previous research. We were able to include parents of survivors attending and not attending clinic-based follow-up, and included prospectively collected data from the SCCR and from two questionnaires from the SCCSS. The response rate was good $(67 \%)$.

Follow-up is an important aspect of quality of survivorship. In the transitioning phase from child to adult care it is important to not only meet survivors' or providers' preferences, but also parents' preferences for the organization of follow-up care. This might avoid a future loss to follow-up. We showed that many parents prefer a clinic-based model of follow-up by pediatric oncologists or a multidisciplinary team. However, parents also valued the follow-up care model according to which their child is followed up.

\section{Acknowledgements:}

We thank all parents of survivors for participating in our survey, the study team of the Swiss Childhood Cancer Survivor Study (Erika Brantschen Berclaz, Micòl Gianinazzi, Julia Koch, Fabienne Liechti, Anna Hohn, Zina HegBachar), the data managers of the Swiss Pediatric Oncology Group (Claudia Anderegg, Nadine Beusch, Rosa-Emma Garcia, Franziska Hochreutener, Friedgard Julmy, Nadine Lanz, Heike Markiewicz, Genevieve Perrenoud, Annette Reinberger, Renate Siegenthaler, Verena Stahel, and Eva Maria Tinner), and the team of the Swiss Childhood Cancer Registry (Vera Mitter, Elisabeth Kiraly, Marlen Spring, Christina Krenger, Priska Wölfli).

Conflict of interest statement: There are no conflicts of interest for any of the authors.

\section{REFERENCES}

Absolom, K., Greenfield, D., Ross, R., Horne, B., Davies, H., Glaser, A., . . . Eiser, C. (2006). Predictors of clinic satisfaction among adult survivors of childhood cancer. Eur J Cancer, 42(10), 1421-1427. doi:10.1016/j.ejca.2006.01.053 
Aslett, H., Levitt, G., Richardson, A., \& Gibson, F. (2007). A review of long-term follow-up for survivors of childhood cancer. Eur J Cancer, 43(12), 1781-1790. doi:10.1016/j.ejca.2007.04.009

Bhatia, S., \& Meadows, A. T. (2006). Long-term follow-up of childhood cancer survivors: Future directions for clinical care and research. Pediatric Blood \& Cancer, 46(2), 143-148.

Blaauwbroek, R., Tuinier, W., Meyboom-de Jong, B., Kamps, W. A., \& Postma, A. (2008). Shared care by paediatric oncologists and family doctors for longterm follow-up of adult childhood cancer survivors: a pilot study. Lancet Oncol, 9(3), 232-238.

Blaauwbroek, R., Zwart, N., Bouma, M., Meyboomde Jong, B., Kamps, W., \& Postma, A. C. G. C. (2007). The willingness of general practitioners to be involved in the follow-up of adult survivors of childhood cancer. J Cancer Surviv, 1, 292-297.

Broadbent, E., Petrie, K. J., Main, J., \& Weinman, J. (2006). The brief illness perception questionnaire. $J$ Psychosom Res, 60(6), 631-637. doi:10.1016/j.jpsychores.2005.10.020

Carlson, C. A., Hobbie, W. L., Brogna, M., \& Ginsberg, J. P. (2008). A multidisciplinary model of care for childhood cancer survivors with complex medical needs. J Pediatr Oncol Nurs, 25(1), 7-13. doi:10.1177/1043454207311741

Children's Oncology Group. (2008). Long-Term Follow-Up Guidelines for Survivors of Childhood, Adolescent, and Young Adult Cancers V3.0. Retrieved from http://www.survivorshipguidelines.org

Christen, S., Vetsch, J., Mader, L., Dehler, S., Korol, D., Kuehni, C., . . . Michel, G. (2016). Preferences for the organization of long-term follow-up in adolescent and young adult cancer survivors. Support Care Cancer. doi:10.1007/s00520-0163157-7

Earle, E. A., Davies, H., Greenfield, D., Ross, R., \& Eiser, C. (2005). Follow-up care for childhood cancer survivors: a focus group analysis. Eur $J$ Cancer, 41(18), 2882-2886. doi:10.1016/j.ejca.2005.08.028

Edgar, A., \& Wallace, W. (2008). Long-term followup of survivors of childhood cancer. $J R$ Coll Physicians Edinb, 38(3), 246-250.

Eiser, C., Absolom, K., Greenfield, D., Glaser, A., Horne, B., Waite, H., . . . Davies, H. (2006). Followup after childhood cancer: evaluation of a three-level model. Eur J Cancer, 42(18), 3186-3190. doi:10.1016/j.ejca.2006.08.001

Eiser, C., Levitt, G., Leiper, A., Havermans, T., \& Donovan, C. (1996). Clinic audit for long-term survivors of childhood cancer. Arch Dis Child, 75(5), 405-409.

Haddy, R. I., \& Haddy, T. B. (2010). Lifetime followup care after childhood cancer. J Am Board Fam Med, 23(5), 647-654. doi:10.3122/jabfm.2010.05.100031

Heirs, M., Suekarran, S., Slack, R., Light, K., Gibson, F., Glaser, A., . . . Phillips, R. (2013). A systematic review of models of care for the follow-up of childhood cancer survivors. Pediatr Blood Cancer, 60(3), 351-356. doi:10.1002/pbc. 24253

Horowitz, M. E., Fordis, M., Krause, S., McKellar, J., \& Poplack, D. G. (2009). Passport for care: implementing the survivorship care plan. J Oncol Pract, 5(3), 110-112. doi:10.1200/jop.0934405

Hudson, M. M., Ness, K. K., Gurney, J. G., Mulrooney, D. A., Chemaitilly, W., Krull, K. R., . . . Robison, L. L. (2013). Clinical ascertainment of health outcomes among adults treated for childhood cancer. JAMA, 309(22), 2371-2381. doi:10.1001/jama.2013.6296

James, N. D., Guerrero, D., \& Brada, M. (1994). Who should follow up cancer patients? Nurse specialist based outpatient care and the introduction of a phone clinic system. Clin Oncol (R Coll Radiol), 6(5), 283287.

Kuehni, C. E., Rueegg, C. S., Michel, G., Rebholz, C. E., Strippoli, M.-P. F., Niggli, F. K., . . . for the Swiss Paediatric Oncology Group. (2012a). Cohort profile: The Swiss Childhood Cancer Survivor Study. Int $J$ Epidemiol, 41(6), 1553-1564. doi:10.1093/ije/dyr142

Kuehni, C. E., Strippoli, M.-P. F., Rueegg, C. S., Rebholz, C. E., Bergstraesser, E., Grotzer, M., . . . Michel, G. (2012b). Educational achievement in Swiss childhood cancer survivors compared with the general population. Cancer, 118(5), 1439-1449. doi:10.1002/cncr.26418

Lawrence, R. A., McLoone, J. K., Wakefield, C. E., \& Cohn, R. J. (2016). Primary Care Physicians' Perspectives of Their Role in Cancer Care: A Systematic Review. $J$ Gen Intern Med. doi:10.1007/s11606-016-3746-7

Mertens, A. C., Cotter, K. L., Foster, B. M., Zebrack, B. J., Hudson, M. M., Eshelman, D., . . . Oeffinger, K. C. (2004). Improving health care for adult survivors of childhood cancer: recommendations from a delphi panel of health policy experts. Health Policy, 69(2), 169-178. doi:10.1016/j.healthpol.2003.12.008

Michel, G., Gianinazzi, M. E., Eiser, C., Bergstraesser, E., Vetsch, J., von der Weid, N., \& Kuehni, C. E. (2016). Preferences for long-term follow-up care in childhood cancer survivors. Eur $J$ Cancer Care (Engl). doi:10.1111/ecc. 12560

Michel, G., Greenfield, D. M., Absolom, K., Ross, R. J., Davies, H., \& Eiser, C. (2009). Follow-up care after childhood cancer: Survivors' expectations and preferences for care. Eur J Cancer, 45(9), 16161623

Michel, G., von der Weid, N. X., Zwahlen, M., Adam, M., Rebholz, C. E., \& Kuehni, C. E. (2007). The Swiss Childhood Cancer Registry: rationale, organisation and results for the years 2001-2005. Swiss Medical Weekly, 137(35-36), 502-509.

Michel, G., von der Weid, N. X., Zwahlen, M., Redmond, S., Strippoli, M.-P. F., \& Kuehni, C. E. (2008). Incidence of childhood cancer in Switzerland: The Swiss childhood cancer registry. Pediatr Blood Cancer, 50(1), 46-51. doi:DOI 10.1002/pbc.21129 
Oeffinger, K. C., Mertens, A. C., Sklar, C. A., Kawashima, T., Hudson, M. M., Meadows, A. T., . . . Robison, L. L. (2006). Chronic health conditions in adult survivors of childhood cancer. $N$ Engl $\mathrm{J} \mathrm{Med,}$ 355(15), 1572-1582.

Rebholz, C. E., von der Weid, N. X., Michel, G., Niggli, F. K., Kuehni, C. E., \& Swiss Pediatric Oncology, G. (2011). Follow-up care amongst longterm childhood cancer survivors: a report from the Swiss Childhood Cancer Survivor Study. Eur J Cancer, 47(2), 221-229. doi:10.1016/j.ejca.2010.09.017

Reulen, R. C., Winter, D. L., Frobisher, C., Lancashire, E. R., Stiller, C. A., Jenney, M. E., .. . Hawkins, M. M. C. Long-term cause-specific mortality among survivors of childhood cancer. JAMA, 304, 172-179.

Schmidt, D., Anderson, L., Bingen, K., Hoag, J., Kupst, M. J., \& Warwick, A. B. (2010). Late effects in adult survivors of childhood cancer: considerations for the general practitioner. $W M J$, 109(2), 98-107.

Scottish Intercollegiate Guidelines Network (SIGN). (2004). Long term follow-up of survivors of childhood cancer. A national clinical guideline, No. $76 . \quad$ Retrieved from http://www.sign.ac.uk/pdf/sign132.pdf

Steliarova-Foucher, E., Stiller, C., Lacour, B., \& Kaatsch, P. (2005). International Classification of Childhood Cancer, third edition. Cancer, 103(7), 1457-1467.
Taylor, N., Absolom, K., Snowden, J., Eiser, C., \& Late Effects Group, S. (2012). Need for psychological follow-up among young adult survivors of childhood cancer. Eur $J$ Cancer Care (Engl), 21(1), 52-58. doi:10.1111/j.13652354.2011.01281.x

Vetsch, J., Rueegg, C. S., Mader, L., Bergstraesser, E., Rischewski, J., Kuehni, C. E., \& Michel, G. (2016). Follow-up care of young childhood cancer survivors: attendance and parental involvement. Support Care Cancer. doi:10.1007/s00520-0163121-6

Wallace, W. H., Thompson, L., Anderson, R. A., \& Guideline Development, G. (2013). Long term follow-up of survivors of childhood cancer: summary of updated SIGN guidance. BMJ, 346, f1 190. doi:10.1136/bmj.f1190

Wallace, W. H. B., Blacklay, A., Eiser, C., Davies, H., Hawkins, M., Levitt, G. A., . . . on behalf of the Late Effects Committee of the United Kingdom Children's Cancer Study Group (UKCCSG). (2001). Developing strategies for long term follow up of survivors of childhood cancer. BMJ, 323(7307), 271-274.

Zebrack, B. J., Eshelman, D. A., Hudson, M. M., Mertens, A. C., Cotter, K. L., Foster, B. M., . . . Oeffinger, K. C. (2004). Health care for childhood cancer survivors: insights and perspectives from a Delphi panel of young adult survivors of childhood cancer. $\quad$ Cancer, 100(4), 843-850. doi:10.1002/cncr.20033 
Table 1. Characteristics of the study population, comparing parents participating and not participating in the questionnaire survey

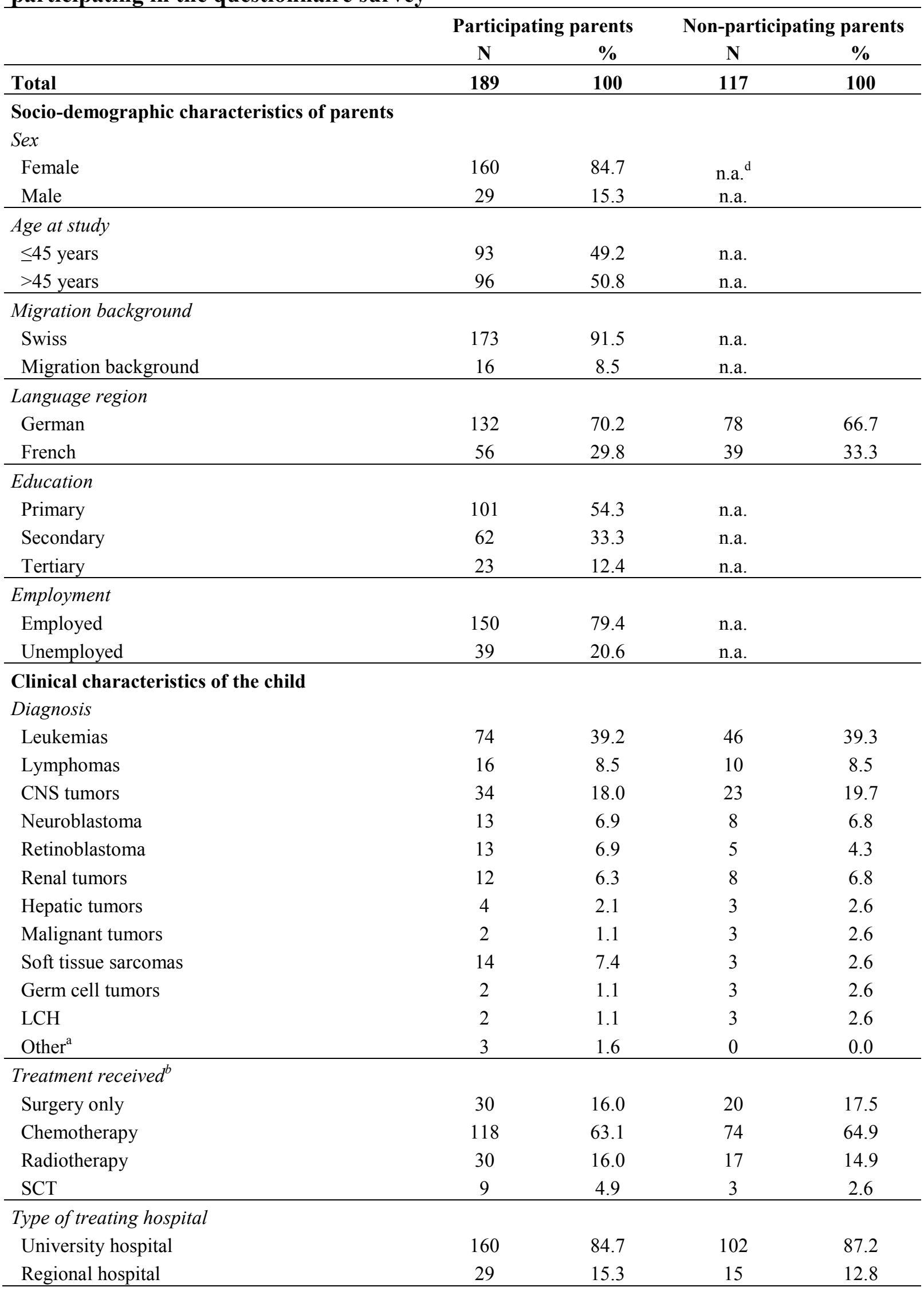


Table 1 contd.

\begin{tabular}{|c|c|c|c|c|}
\hline & \multicolumn{2}{|c|}{ Participating parents } & \multicolumn{2}{|c|}{ Non-participating parents } \\
\hline & $\mathbf{N}$ & $\%$ & $\mathbf{N}$ & $\%$ \\
\hline Total & 189 & 100 & 117 & 100 \\
\hline \multicolumn{5}{|l|}{ Child's age at diagnosis } \\
\hline $0-1$ years & 58 & 30.7 & 35 & 29.9 \\
\hline $2-4$ years & 82 & 43.4 & 48 & 41.0 \\
\hline $5+$ years & 49 & 25.9 & 34 & 29.1 \\
\hline \multicolumn{5}{|l|}{ Time since diagnosis } \\
\hline 5-9 years & 64 & 33.9 & 38 & 32.5 \\
\hline $10-14$ years & 96 & 50.8 & 58 & 49.6 \\
\hline $15-17$ years & 29 & 15.3 & 21 & 17.9 \\
\hline \multicolumn{5}{|l|}{ Child's age at study } \\
\hline$<14$ years & 60 & 31.8 & 36 & 30.8 \\
\hline $14-15$ years & 43 & 22.7 & 17 & 14.5 \\
\hline$>15$ years & 86 & 45.5 & 64 & 54.7 \\
\hline \multicolumn{5}{|l|}{ Relapse } \\
\hline No & 168 & 88.9 & 104 & 88.9 \\
\hline Yes & 21 & 11.1 & 13 & 11.1 \\
\hline \multicolumn{5}{|c|}{ Parent-reported late effects } \\
\hline No & 100 & 54.4 & 68 & 64.2 \\
\hline Yes & 84 & 45.6 & 38 & 35.8 \\
\hline \multicolumn{5}{|c|}{ Parental involvement in follow-up } \\
\hline No & 10 & 7.1 & n.a. & \\
\hline Yes & 130 & 92.9 & n.a. & \\
\hline \multicolumn{5}{|l|}{ Follow-up attendance } \\
\hline Yes & 141 & 74.6 & n.a. & \\
\hline \multirow[t]{3}{*}{ No } & 48 & 25.4 & n.a. & \\
\hline & \multicolumn{2}{|c|}{ Participants } & \multicolumn{2}{|c|}{ Non-participants ${ }^{\mathrm{a}}$} \\
\hline & Mean & SD & Mean & SD \\
\hline Parent's age & 46.1 & 4.8 & n.a. & n.a. \\
\hline Child's age at study & 14.7 & 1.8 & 15.0 & 1.9 \\
\hline Child's age at diagnosis & 3.4 & 2.2 & 3.6 & 2.4 \\
\hline Time since diagnosis & 11.3 & 2.5 & 11.4 & 2.5 \\
\hline
\end{tabular}

Note: Percentages are based upon available data for each variable. Abbreviations: CNS, Central Nervous System; LCH, Langerhans Cell Histiocytosis; n.a., not available; N, Number; SCT, Stem Cell Transplantation; SD, Standard Deviation; ${ }^{\mathrm{a} O t h e r: ~ m a l i g n a n t ~ e p i t h e l i a l ~ n e o p l a s m s, ~ m a l i g n a n t ~ m e l a n o m a s ~ a n d ~ o t h e r ~ o r ~ u n s p e c i f i e d ~ m a l i g n a n t ~}$ neoplasms; ${ }^{b}$ Chemotherapy may include surgery, radiotherapy may include chemotherapy and/or surgery. 
Table 2. Factors associated with preferences for follow-up care by generalists (GP/Telephone-led follow-up) versus specialists (from univariable logistic regression models)

\begin{tabular}{|c|c|c|c|c|c|c|}
\hline & \multicolumn{3}{|c|}{$\begin{array}{c}\text { Preference for } \\
\text { generalist follow-up }\end{array}$} & \multicolumn{3}{|c|}{ Univariable regression } \\
\hline & N Total & $\mathbf{N}$ & $\%$ & OR & $95 \% \mathrm{CI}$ & p \\
\hline \multicolumn{7}{|c|}{ Socio-demographic characteristics of parents } \\
\hline $\operatorname{Sex}$ & & & & & & 0.300 \\
\hline Female & 158 & 29 & 18.4 & 1 & & \\
\hline Male & 28 & 3 & 10.73 & 0.53 & $0.15-1.89$ & \\
\hline Age at study & & & & & & 0.894 \\
\hline$\leq 45$ years & 91 & 16 & 17.6 & 1 & & \\
\hline$>45$ years & 95 & 16 & 16.8 & 0.95 & $0.44-2.03$ & \\
\hline Migration background & & & & & & 0.176 \\
\hline Swiss & 170 & 31 & 18.2 & 1 & & \\
\hline Immigrant & 16 & 1 & 6.3 & 0.30 & $0.04-2.35$ & \\
\hline Language region & & & & & & 0.127 \\
\hline German & 131 & 19 & 14.5 & 1 & & \\
\hline French & 54 & 13 & 24.1 & 1.86 & $0.85-4.12$ & \\
\hline Education & & & & & & 0.379 \\
\hline Primary & 100 & 20 & 20.0 & 1 & & \\
\hline Secondary & 60 & 7 & 11.7 & 0.53 & $0.21-1.34$ & \\
\hline Tertiary & 23 & 4 & 17.4 & 0.84 & $0.26-2.75$ & \\
\hline Employment & & & & & & 0.490 \\
\hline Employed & 148 & 24 & 16.2 & 1 & & \\
\hline Unemployed & 38 & 8 & 21.1 & 1.38 & $0.56-3.37$ & \\
\hline \multicolumn{7}{|c|}{ Clinical characteristics of the child } \\
\hline Diagnosis & & & & & & 0.657 \\
\hline Leukemia & 72 & 16 & 22.2 & 1 & & \\
\hline Lymphoma & 16 & 3 & 18.7 & 0.81 & $0.20-3.19$ & \\
\hline CNS tumor & 34 & 6 & 17.7 & 0.75 & $0.26-2.13$ & \\
\hline Neuroblastoma & 12 & 2 & 16.7 & 0.70 & $0.14-3.53$ & \\
\hline Bone tumor/STS & 16 & 1 & 6.3 & 0.23 & $0.03-1.90$ & \\
\hline Other tumor $^{\mathrm{a}}$ & 24 & 3 & 12.5 & 0.5 & $0.13-1.89$ & \\
\hline Treatment received $^{b}$ & & & & & & 0.297 \\
\hline Surgery & 29 & 7 & 24.1 & 1 & & \\
\hline Chemotherapy & 117 & 19 & 16.2 & 0.61 & $0.23-1.63$ & \\
\hline Radiotherapy & 29 & 2 & 6.9 & 0.23 & $0.04-1.24$ & \\
\hline SCT & 9 & 2 & 22.2 & 0.90 & $0.15-5.36$ & \\
\hline Type of treating hospital & & & & & & 0.080 \\
\hline University hospital & 157 & 30 & 19.1 & 1 & & \\
\hline Regional hospital & 29 & 2 & 6.9 & 0.31 & $0.07-1.39$ & \\
\hline Child's age at diagnosis & & & & & & 0.214 \\
\hline $0-1$ years & 56 & 6 & 10.7 & 1 & & \\
\hline $2-4$ years & 82 & 18 & 21.9 & 2.34 & $0.87-6.34$ & \\
\hline $5+$ years & 48 & 8 & 16.7 & 1.67 & $0.53-5.20$ & \\
\hline Child's age at study & & & & & & 0.381 \\
\hline$<14$ years & 60 & 8 & 13.3 & 1 & & \\
\hline $14-15$ years & 42 & 6 & 14.3 & 1.08 & $0.35-3.39$ & \\
\hline$>15$ years & 84 & 18 & 21.4 & 1.77 & $0.71-4.40$ & \\
\hline Time since diagnosis & & & & & & 0.556 \\
\hline $5-9$ years & 64 & 11 & 17.2 & 1 & & \\
\hline $10-14$ years & 94 & 18 & 19.2 & 1.14 & $0.50-2.62$ & \\
\hline $15-17$ years & 28 & 3 & 10.7 & 0.58 & $0.15-0.40$ & \\
\hline
\end{tabular}


Table 2 contd.

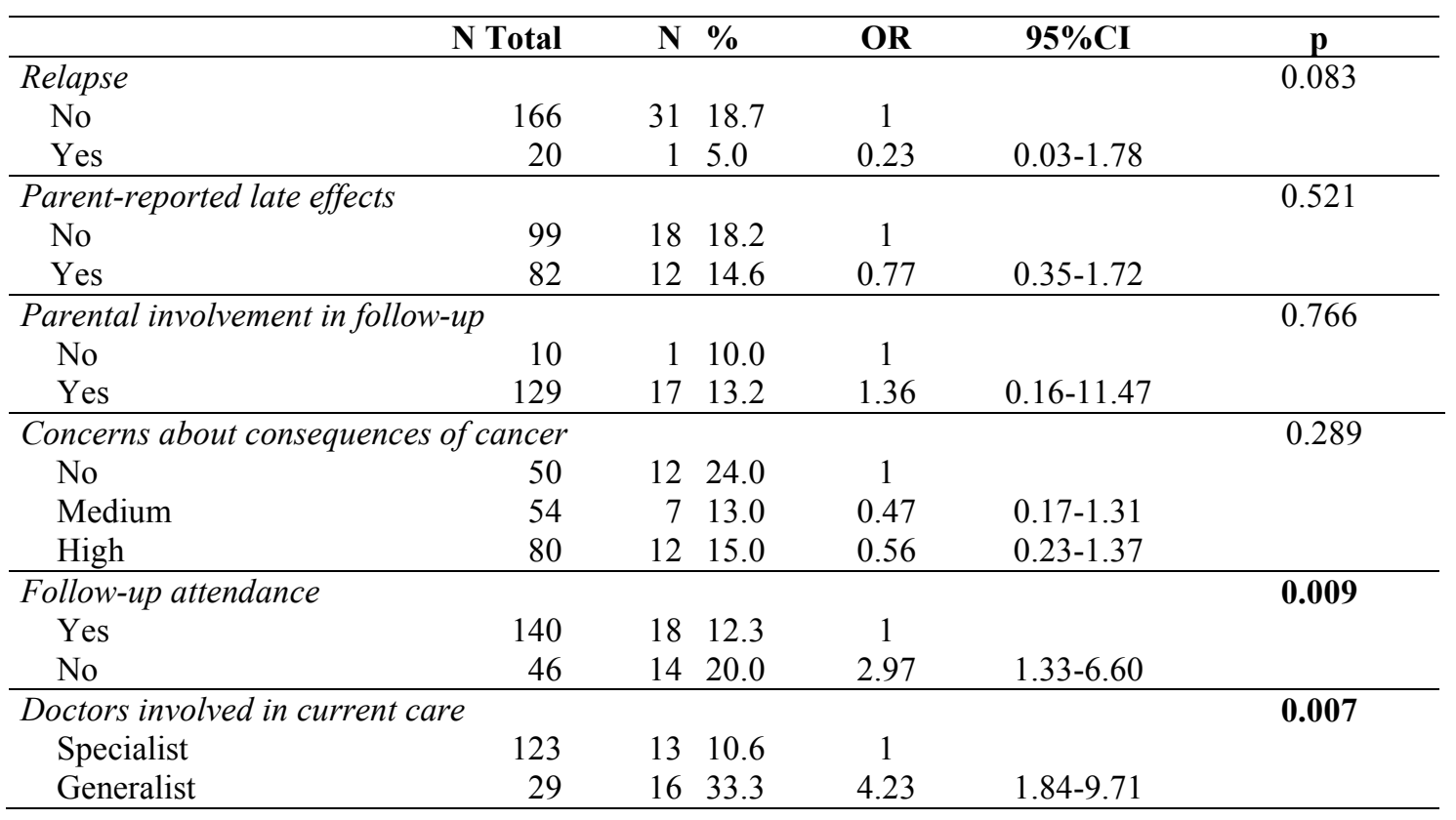

Note: Numbers for each outcome vary because not all participants answered each question. Percentages are based upon available data for each variable. Abbreviations: CI, Confidence Interval; CNS, Central Nervous System; GP,

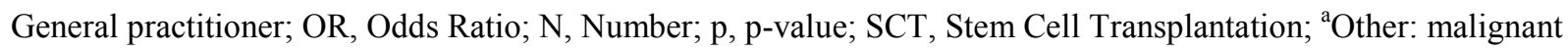
epithelial neoplasms, malignant melanomas and other or unspecified malignant neoplasms; ${ }^{\mathrm{b}} \mathrm{Chemotherapy} \mathrm{may}$ include surgery, radiotherapy may include chemotherapy and/or surgery; 
Figure 1. Parents' preferences for the organization of follow-up care

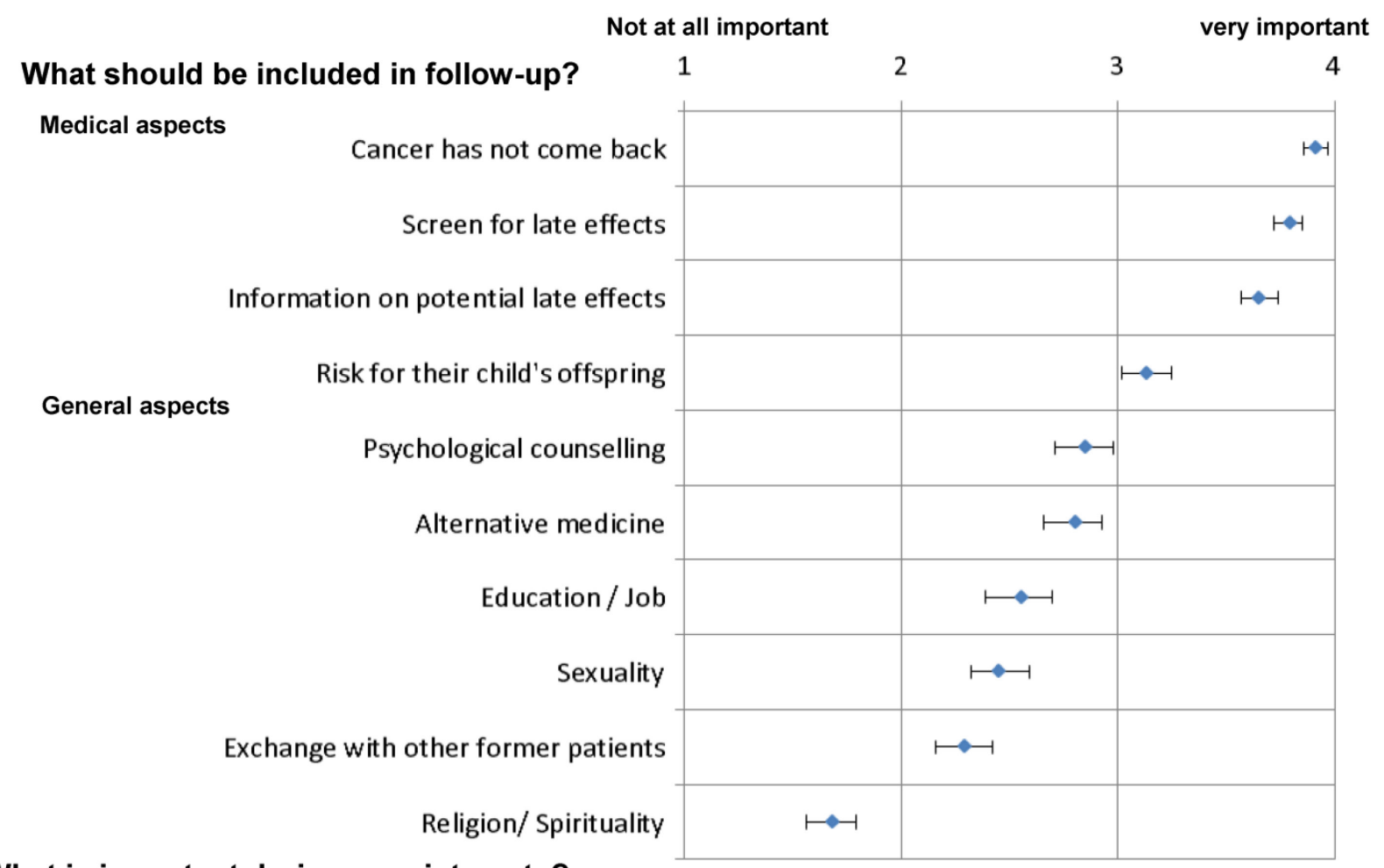

What is important during appointments?

\begin{tabular}{|c|c|c|}
\hline Patient is taken seriously & & Hor \\
\hline Competent staff & & $1+\infty$ \\
\hline Quality of relationship to medical staff & & $\mapsto \mapsto$ \\
\hline Paid by insurance & & $1+-1$ \\
\hline Same doctor & & $\mapsto-1$ \\
\hline Regular appointments & & $\mapsto \mapsto$ \\
\hline No long waiting time & & $\mapsto-1$ \\
\hline Same nurse & $\mapsto-1$ & \\
\hline Short consultation & $\mapsto \bullet$ & \\
\hline Meet former patients & $\mapsto-1$ & \\
\hline
\end{tabular}




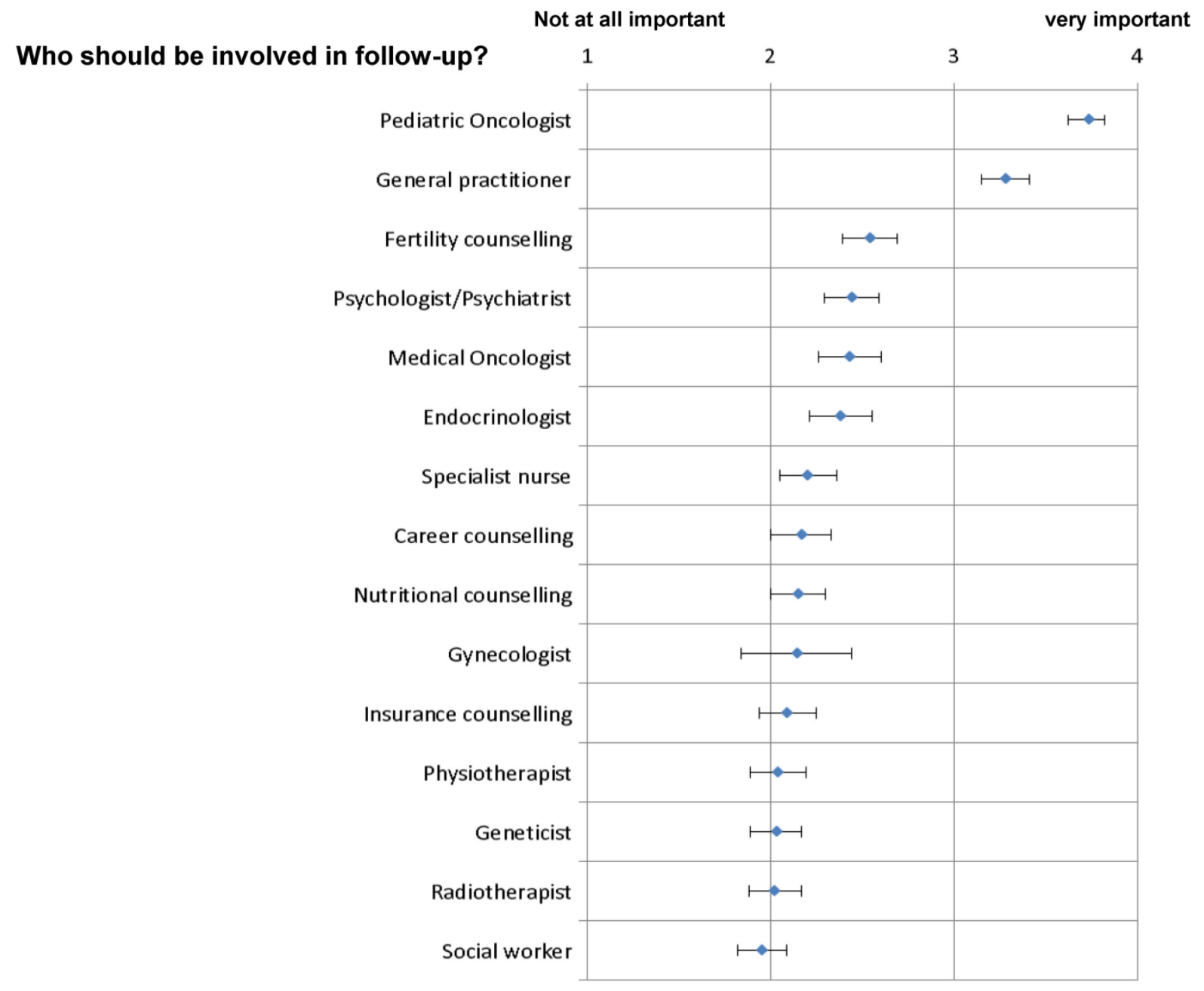


Figure 2. Parents' preferred model of follow-up care

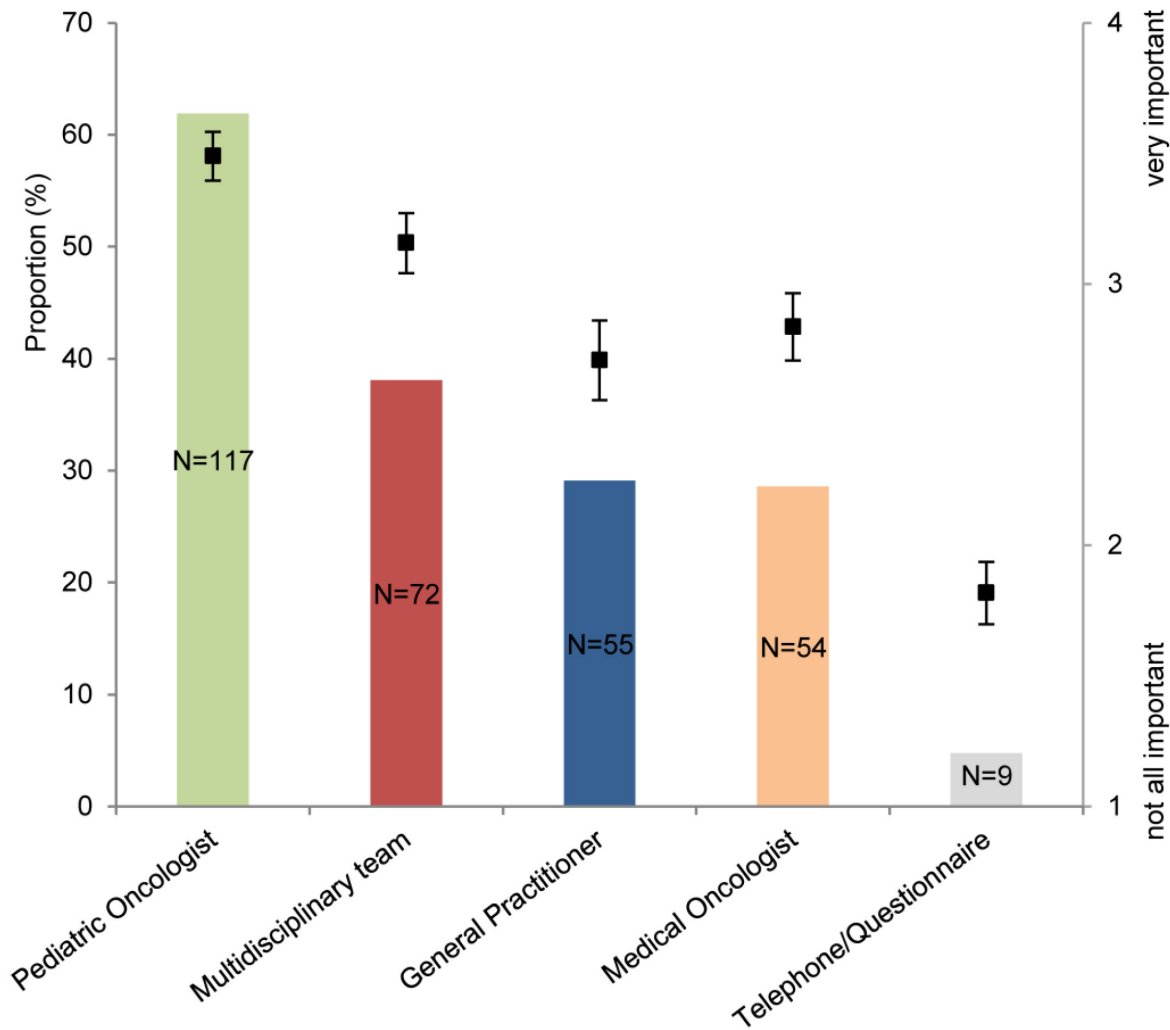

Figure 2 shows on the left side the proportion (bars) of parents rating the respective model as their most preferred follow-up care model (highest mean score among all the models; parents could have more than one preferred model reaching the same highest score), and on the right side the four point likert scale and the mean values (square symbols)

Abbreviations: $\mathrm{N}=$ number 
Figure 3. Parents' preferred follow-up care model stratified by the model their child is currently attending (Specialist vs generalist)

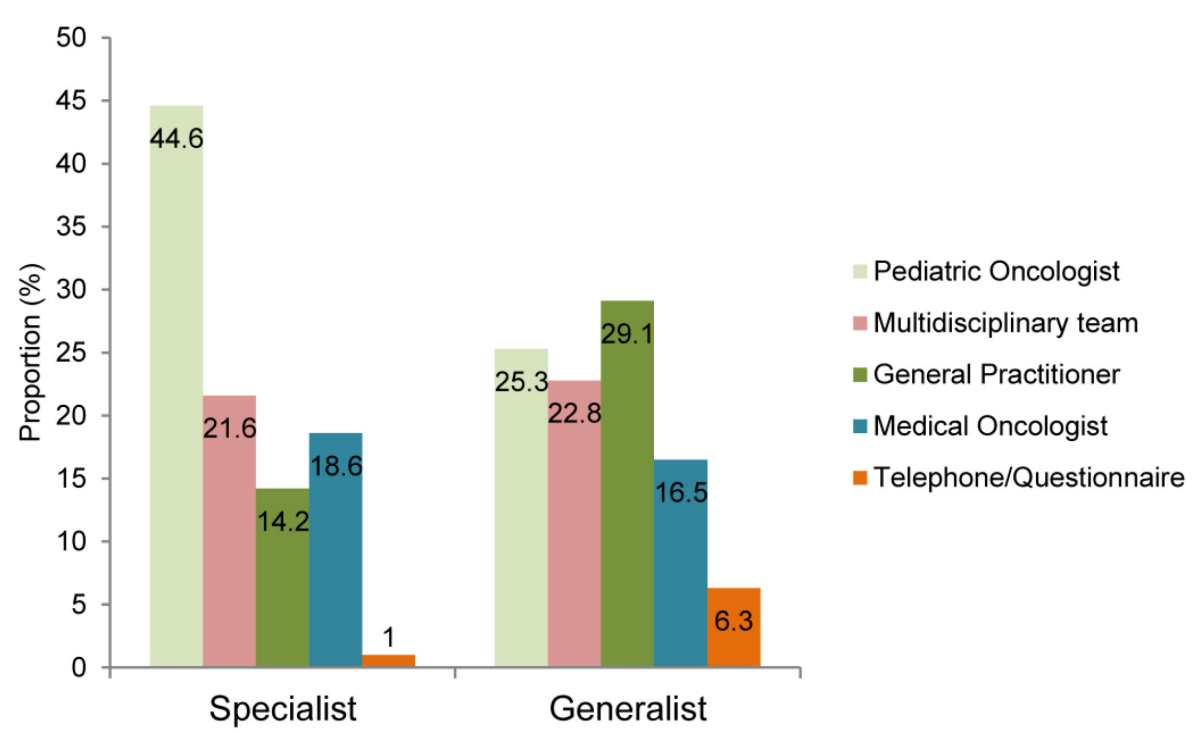

Figure 3 shows the proportion of parents rating the respective model as their preferred follow-up care model stratified by the model their child is currently attending (highest mean score among all the models; parents could have more model which they preferred most) 